\title{
Design of Microstrip Patch Antenna Based on FSS for 5G and Wimax Applications
}

\author{
Pronami Bora, P. Pardhasaradhi, B.T.P. Madhav \\ Antennas and Liquid Crystals Research Center, Department of ECE, Koneru Lakshmaiah Education Foundation, \\ Vaddeswaram, A.P. India
}

(Received 05 January 2021; revised manuscript received 14 February 2021; published online 25 February 2021)

\begin{abstract}
This work offers an optimized microstrip patch antenna for 5G and Wi-Max applications. The proposed design is based on rectangular patch antenna embedded with frequency selective surface consisting of an array of $4 \times 4$ patches to increase the gain of the antenna by more than $7 \mathrm{~dB}$. FSS layer is mounted under the microstrip patch of the antenna which provides a stop band response with more than $-60 \mathrm{~dB}$ loss at the frequency range $3.5 \mathrm{GHz}$ and more than $30 \mathrm{~dB}$ at $6 \mathrm{GHz}$.
\end{abstract}

Keywords: Frequency Selective Surface (FSS), Rectangular patch, Microstrip, Wi-Max, 5G.

\section{INTRODUCTION}

The development of FSS has recently enticed attention among various researchers around the world. There is a massive demand for vast bandwidth ranges ranging from $3.1 \mathrm{GHz}$ to $10.6 \mathrm{GHz}$ for evolving technologies in connectivity. In the literature, various solutions relevant to the creation of FSS layer have been suggested. In Ref. [1] a modern miniaturized FSS for broadband requirements for UWB applications consisting of garland-liking designs printed on both side of the patch is suggested. This design provides a good impedance matching of $-60 \mathrm{~dB}$ at $3.5 \mathrm{GHz}$ resonating frequency. A three-layer FSS, providing ultra-wide band response (UWB) is designed in Ref. [2]. In Ref. [3] 3-D frequency selective sheet, with numerous transmission zeros and pseudo-cellulary surfaces, the layers use single, rectangular patches and one or two notches and give multi-band responses. By cascading them UWB responses cover the $4.05 \mathrm{GHz}-14.12 \mathrm{GHz}$ range and the $5.05 \mathrm{GHz}-15 \mathrm{GHz}$ range for horizontal polarization. In Ref. [4] a curved dome FSS has been recorded with additional wideband applications. The experimental work has been performed on curved wider-band FSS. The FSS framework is built with a ring patch of the identical size on the dome- shaped substratum predicted. This arrangement has a broader frequency band $(7.09 \mathrm{GHz})$ in contrast to traditional flat style FSS. Each FSS periodic cell comprises of a square metal patch with back to back slots of variable duration bands. With a total of seven reflex bands and a reduced patch length, this built FSS is usable. This work suggests a new concept of FSS utilizing unit cells of metallic rectangular patches on the substratum. The waveport study of the system beneath the antenna is a periodic sequence of the unit module. The microstrip antenna in combination with the FSS provides an increased benefit. The proposed design based on FSS presents a return loss of more than $30 \mathrm{~dB}$ in the desirable band of 3.5-6 GHz. The experimental results have been reported for both the infinite array study and the lumped port study. The levels of radiation in the $\mathrm{E}$ and $\mathrm{H}$ planes have been observed which shows good radiation efficiency in the desired operating frequency

\section{FSS BASED DESIGN}

\subsection{Infinite Array Analysis of the Unit Cell}

Frequency selective surfaces are frequent geometries which function as electromagnetic filters. The characteristics for transmission and reflection of the FSS system are centred on the device form of the grid, the patches of which represent a desired frequency band and the apertures of the system transmit a certain frequency band. In this work, the SFL is built on a substrate of $1.57 \mathrm{~mm}$ thick. The substrate selected is FR4-epoxy with and a dielectric constant of 4.4 which is the most commonly available substrate. The unit cell is a mixture of four rectangular metal patches of 10 (in), thickness, configuration which is of 10 rectangular metallic patch(s). The components must be placed nearer than $\lambda / 2$ to accommodate the grating lobes. Resonance from simulation tests can be detected at $3.5 \mathrm{GHz}$. The master and the slave limits are specified on the model for infinite array analysis such that each master boundary contains a slave line in line with the norm. Within the HFSS, both the top and the bottom faces are described at $20 \mathrm{~mm}$ for floquet mode analysis.

There has been a return loss in excess of $30 \mathrm{~dB}$, which proves that the FSS acts as a perfect band stop filter. The reflecting characteristics degrade $-10 \mathrm{~dB}$ bandstand characteristics in frequency range of 7 $8 \mathrm{GHz}$, and over $8 \mathrm{GHz}$.

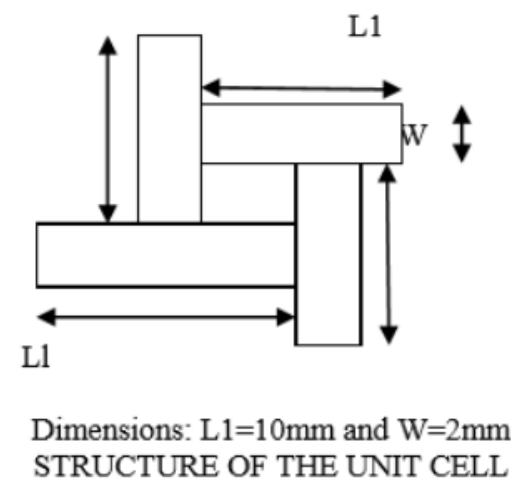

Fig. 1 - Unit Cell Structure 


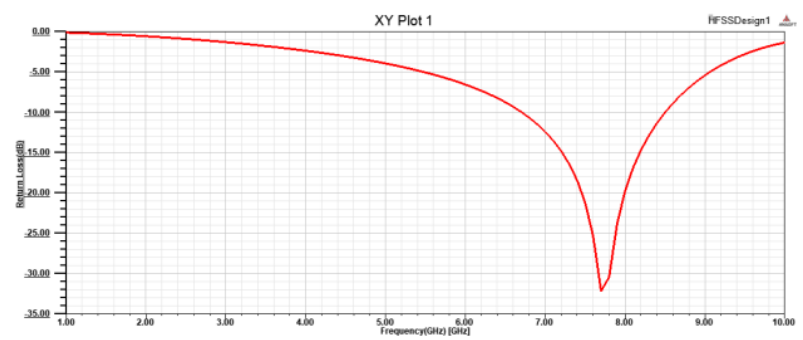

Fig. 2 - Characteristics of Transmission

\subsection{Waveport Analysis [Finite Array Analysis]}

The unit cells are arranged in such a way that they are adjacent to each other which form an arrangement in finite dimensions. The FSS group is encapsulated into four boundary walls, and the $\mathrm{E}$ walls are adjacent to each other. The $\mathrm{H}$ walls are parallel to one another. Therefore, the neighbouring components are neighbouring to one another. Bandwidth between $5.6 \mathrm{GHz}$ and $7-6 \mathrm{GHz}$ is achieved by taking thecharacteristics of transmission into consideration over a limited number over 16 unit cells. The transmission characteristics are remarkably greater than the mark it reaches. The propagation properties over a small number of 16 unit cells are taken into account, which results in bandwidth range between 5.6 and $7.6 \mathrm{GHz}$. The features of the transmission are considerably greater than their name. This involves the thickness of the layer, inserting a parasite in either the layout of the coplanar or stack and modifying the shape of a typical radiator patch by attaching slots. The latter solution is especially appealing because it can give an outstanding bandwidth enhancement and retain a single-layer radiation framework to protect the characteristic thin-profile of the antenna

\subsection{Design of the Microstrip Antenna}

The propagation properties over a small number of 16 unit cells are taken into account, which results in bandwidth range between 5.2 and $6.8 \mathrm{GHz}$. The features of the transmission are considerably greater than their name. This involves the thickness of the layer, inserting a parasite in either the layout of the coplanar or stack and modifying the shape of a typical radiator patch by attaching slots. The latter solution is especially appealing because it can give an outstanding bandwidth enhancement and retain a single-layer radiation framework to protect the characteristic thin-profile of the antenna. Figs. 3 and 4 show the structure of microstrip antenna and an unit cell respectively. The antenna dimensions are given in Table 1.

The Microstrip Patch Antenna is commonly used in recent times because of its lightweight, portable nature, low size, low cost of production and easy to use in integrated circuits with microwaves. It has a small gain and impedance bandwidth, as an inherit disadvantage.

\subsection{Integration of the patch antenna with the proposed FSS geometry}

A patch antenna is positioned at a separation of
$15 \mathrm{~mm}$ from the FSS. HFSS is used for the simulation of the design of the antenna and of the FSS. It is noted, that the framework of the composite has radiation patterns. It is observed that the antenna gain is enhanced with the combination with a FSS.

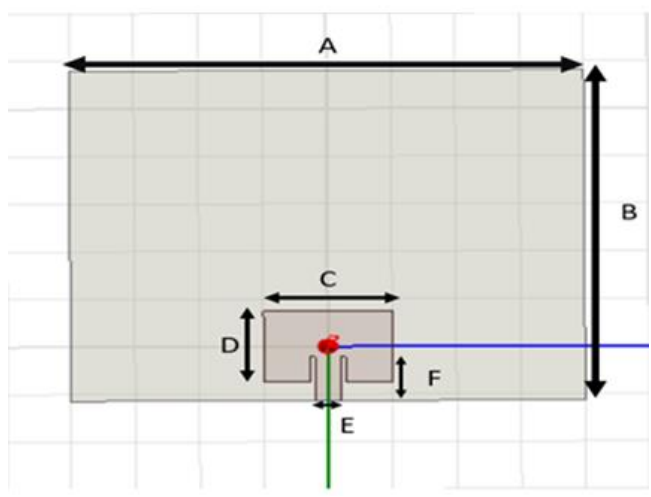

Fig. 3 - Geometry of the microstrip antenna

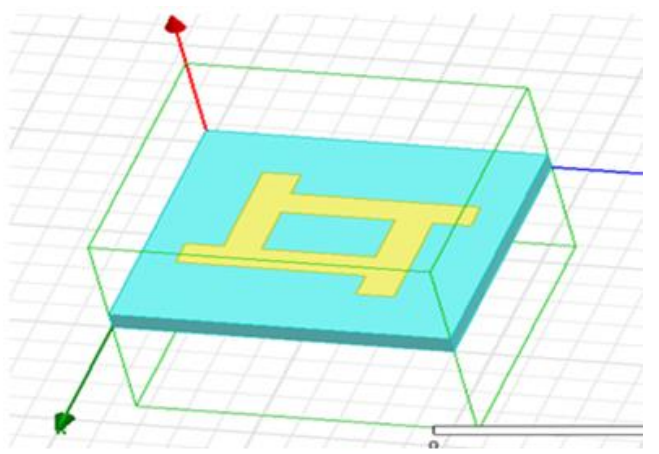

Fig. 4 - Unit Cell in HFSS

Table 1 - Dimensions of the antenna

\begin{tabular}{|l|l|l|l|l|l|l|}
\hline Dimensions & A & B & C & D & E & F \\
\hline Units $(\mathrm{mm})$ & 80 & 80 & 10 & 7.4 & 2 & 4.6 \\
\hline
\end{tabular}

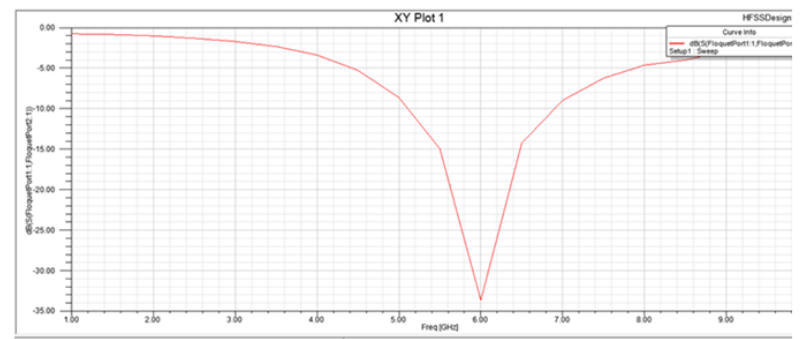

Fig. 5 - Transmission Characteristics with Unit Cell in HFSS

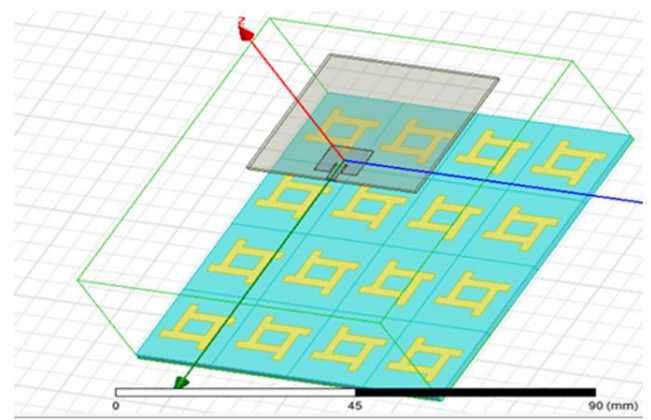

Fig. 6 - Microstrip patch antenna embedded with FSS 


\section{PARAMETRIC ANALYSIS}

The structural parametric study of the antenna indicated was carried out using the FSS system to achieve optimized dimensions. Remember that while one parameter is modified the remainder is held unchanged. Firstly, the antenna efficiency is analyzed with the influence of disruption cells. The efficiency of the antenna is extremely perturbed.

\subsection{Varying the Distance from Patch and FSS}

As seen in the following figure, by varying the distance of the patch and FSS structure from $10 \mathrm{~mm}$ $20 \mathrm{~mm}$ which produces a shift at the lower frequencies.

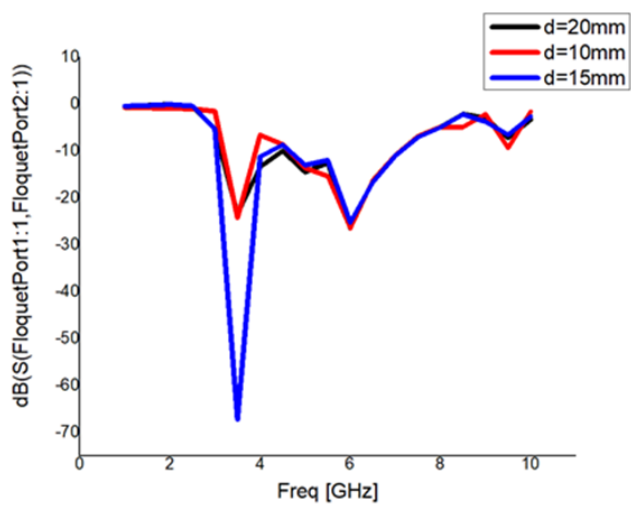

Fig. 7 - S11 analysis of microstrip with FSS by varying distance

\subsection{Varying the Number of Unit Cells in FSS}

Here the return loss response of patch antenna is presented by varying the unit cells of FSS substrate. We can observe from Fig. 8 that the $4 \mathrm{x} 4$ unit cells provide satisfactory results.

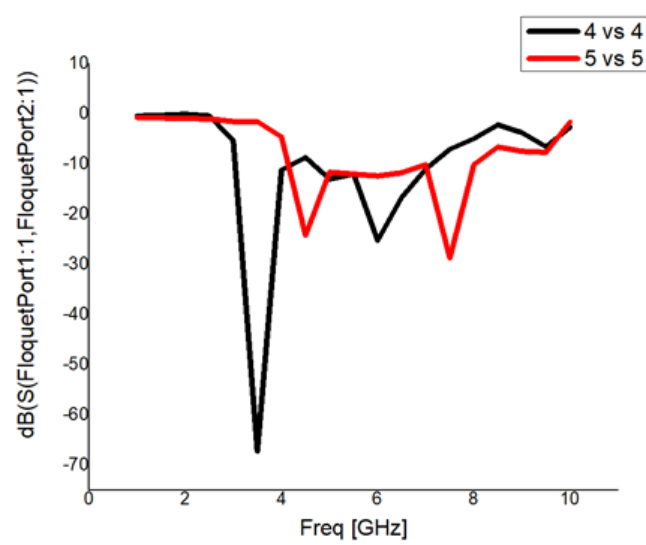

Fig. 8 - S11 analysis of microstrip with FSS by varying number of unit cells

\section{RESULTS}

The antenna integrated is analyzed and measured using HFSS tools. The coefficient of reflection and antenna gain is seen below in Figs. 9 and 10 respectively. It can be observed that a gain of $9 \mathrm{~dB}$ occurs at the resonating frequency of $3.5 \mathrm{GHz}$. Excellent return loss of $60 \mathrm{~dB}$ is obtained at the operating frequencies of
$3.5 \mathrm{GHz}$ and $-30 \mathrm{~dB}$ at $6 \mathrm{GHz}$. In Fig. 10, the simulated pattern radiation for the antenna integrated with FSS substrate indicates a strong pattern radiation with a dumb-bell shaped pattern.

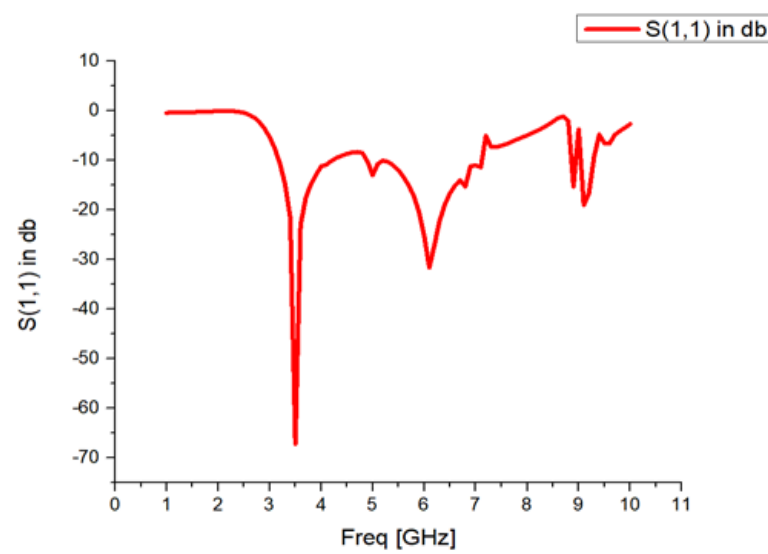

Fig. 9 - S11 analysis of the proposed antenna

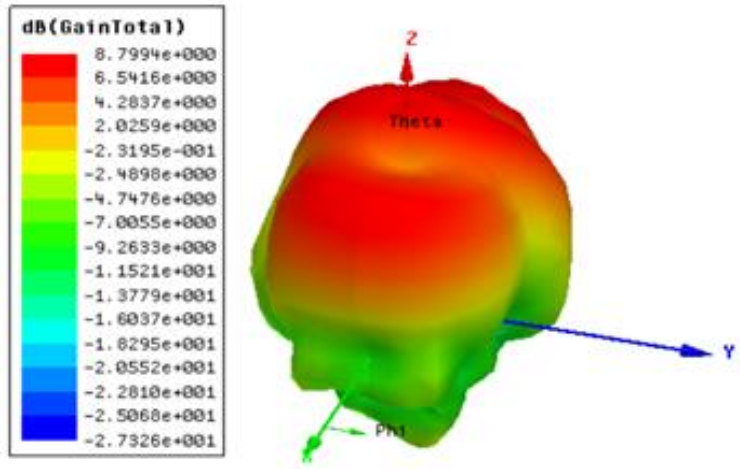

Fig. 10 - Gain of the proposed antenna

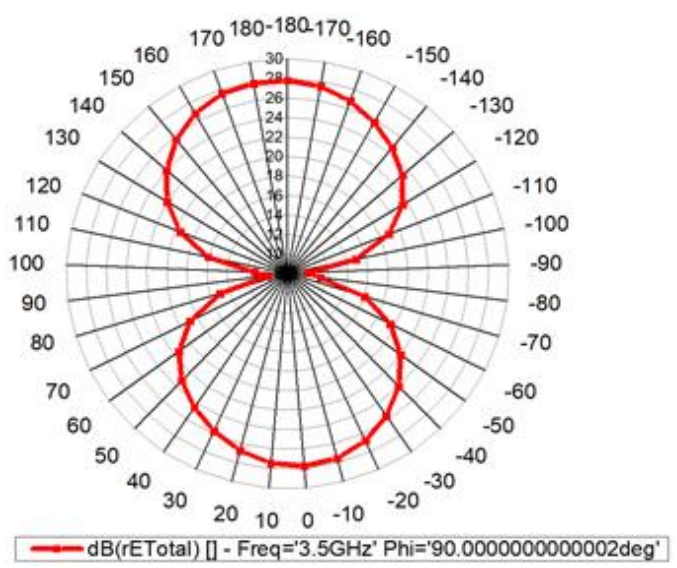

Fig. 11 - Radiation Pattern

\section{CONCLUSION}

The radiology of a combined system indicates that the raise of the antenna undergoes the rise in the frequency band through which the FSS indicates the band-stop response. The FSS parallels the frequency range [3.5 and $6 \mathrm{GHz}$ ] as the EM waves appear on the assembled structures. The FSS indicates the frequency band 3.5 and $6 \mathrm{GHz}$. From E field radiation variations it is observed that the antenna change is decreased by 
$9.2 \mathrm{~dB}$ in 60 degrees, improved by $14 \mathrm{~dB}$ in 0 degrees and improved by $12 \mathrm{~dB}$ in 90 degrees. However, as the duration of the microstrip patch rises, there is a decrement in the operating frequency of the patch. The proposed antenna provides a gain improvement of more

\section{REFERENCES}

1. Sanjay Baisakhiya, RamprabhuSivasamy, MalathiKanagasabai, Sakthivel Periaswamy, Prog. Electromag. Res. Lett. 40, 71 (2013).

2. Francisco Carlos Gurgel da Silva Segundo, Antonio Luiz Pereira de Siqueira Campos, Alfredo Gomes Neto, J. Microwav., Optoel. Electromagn. Appl. 12 No 2 (2013).

3. Vishumendra Thakur, Bimal Raj Dutta, Binod Kumar Kanaujia, Int. J Adv. Res. Electric. Electron. Instr. Eng. 4 No 7 (2015).

4. Pronami Bora, Mona Mudaliar, Yuvraj BaburaoDhanade, K. Sreelakshmi, Chayan Paul, B.T.P. Madhav, Int. J. Eng. Technol. 7 No 1.1, 461 (2018).

5. R. Nakamura, T. Fukusako, IEEE Trans. Antennas Propag. 59 No 6, 2103 (2011)

6. Bernard, G. Chetier, R. Sauleau, IEEE Antennas Wireless Propag. Lett. 10, 1015 (2011).

7. P.V.V. Kishore, G. Anantha Rao, E. Kiran Kumar, M. Teja Kiran Kumar, D. Anil Kumar, Int. J. Intellig. Eng. Syst. than $7 \mathrm{~dB}$ with better performance efficiency. The resonating frequencies of $3.5 \mathrm{GHz}$ and $6 \mathrm{GHz}$ with satisfactory impedance matching makes the proposed antenna suitable for 5G and Wi-Max applications.

11 No 2, 68 (2018)

8. G. Sai Dheeraj, S.S. Raghavarapu, Int. J. Pharmac. Res. 10 No 4, 74 (2018)

9. B.P. Nadh, Progr. Electromagne. Res. M 76, 167 (2018).

10. P. Venu Madhav, M. Siva Ganga Prasad, Int. J. Innovat. Technol. Explor. Eng. 8 No 113373 (2019).

11. D.K. Naik, B.T.P. Madhav, J. Krishna, M. Venkateswara Rao, D.N. Kumar, Y.N. Ram Kumar, D.S. Teja, Int. J. Innovat. Technol Explor. Eng. 8 No 7, 786 (2019).

12. P. Pardhasaradhi, G.K. Sai, D.P. Teja, B. Ganesh, Int. J. Innovat. Technol Explor. Eng. 8 No 7, 2369 (2019).

13. G.B.G. Tilak, S.K. Kotamraju, B.T.P. Madhav, C. Sri Kavya, M. Venkateswara Rao, Int. J. Recent Technol. Eng. 8 No 2, 2333 (2019).

14. C. Sai Ram, N.V.K. Ramesh, B.T.P. Madhav, B. PrudhviNadh, Int. J. Innovat. Technol Explor. Eng. 8 No 8, 449 (2019). 